\title{
What can South Africa contribute to the AIDS epidemic?
}

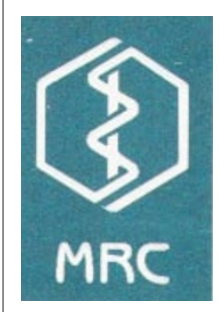

Next month, Malagapuru William Makgoba, professor of pathology at the University of Witwatersrand, will begin a three month co-government of the Medical Research Council (MRC) of South Africa with MRC president Walter Prozesky, beforetaking over the position officially on January 1st 1999.

Although he has made the transition from Transvaal sheep-herder to physician with a Ph.D. from Oxford University, UK and author of several Nature papers, thetask Makgoba now faces is daunting. As leader of the best established statutory research body in sub-Saharan Africa-a region that harbors 90 percent of theworld'sHIV/AIDS population and where patients have no accessto antiretroviral drugsunless they are pregnant women participating in AZT vertical transmission trials-Makgoba must develop a coherent strategy for dealing with the epidemic. And he must achieve this within the first 18 months of his five-year term, if not before, becausein July 2000 the world's attention will be focused more sharply than ever on southern Africa, as attendees of the 13th World AIDSmeeting converge on Durban.

Fortunately, Makgoba will have new support from three key areas. There is now a clear political commitment to fighting the disease. Six months ago, an Inter-governmental Committee on AIDS, chaired by Deputy President Thabo M beki, was created to coordinate all facets of AIDS-related healthcare, prevention, surveillance and research. Such is thelevel of new political awareness that President Nelson Mandela has made himself available for World AIDS day on December 1st.

Secondly, if current discussions of a proposal by French AIDS researcher Luc Montagnier to open a R40 million (US\$6.7 million) HIV research center are successful, the MRC and Makgoba will be charged with managing an internationally high-profile research site in South Africa.

Thirdly, Makgoba will take officeoneyear after a review of the MRC by an international commission, which concluded that theMRC, in comparison with other science councils, is an important structure and should be strengthened by a four-fold

increase in government funding.

But theMRC's prospects havenot al ways been so promising. Ten years ago, it was a behemoth of an apartheid organization that was lumbering, top-heavy and without an effective program of internal research. And although every research organization, except perhaps the USNational Institutes of Health, pleads underfunding, the problem in South Africa was serious enough to threaten the very basis of scientific research.

However, in 1994, the new government brought with it a change in MRC leadership that proved to be so effective that the international review of South Africa's eight science councils requested by the department of Arts, Culture, Science and Technology in November 1997 declared: “In

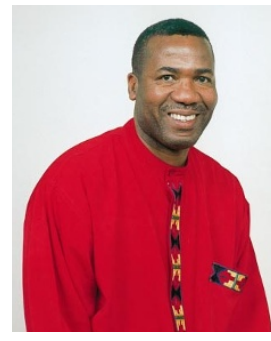

Malagapuru William Makgoba thelast threeyears, the MRC hasundergone substantial transformation." The review committee, chaired by Alan Aderem, professor of immunology at the University of Washington, recommended that the MRC strengthen the university research system by moving resources from intramural programs. "South Africa's scientific infrastructure, particularly in the universities, is very well established and there are some outstanding scientists there," Aderem told Nature M edicine. The recommen ded fourfold increase in government funding was based on evaluations of other science budgets from which money could be transferred. "The money is there and would be well spent, but there are also programsthat build houses, etc. who could also make a compelling argument to put their hands on this money," says Aderem.

The new budget is expected to beannounced by November. In 1998, MRC funds topped R100 million (US\$16.67 million) for the first time -20 percent of this raised through contract research or funding from international sources. The R15 million spent on HIV/AIDS research is derived from the following sources: R2.8million from the government; R4.5 million from the National Department of Health as a one-off payment to develop a national HIV and STD surveillance system; R5 million from the NIH's HIVNET program; R1.7 million from UNAIDSfor micro- bicideand perinatal transmission trials and R1 million from the Wellcome Trust for a community-based study on migrancy and HIV.

Although much is made in the western media of lowering the cost of triple therapy drugs to make them accessible for Africa, researchers there are not relying on this and do not view the drugs as a solution to the continent's AIDS problem, largely because of the degree of compliance they require. "We have decided on vaccination as the only logical way of handling the problem," says Prozesky, who adds "we'll carry on giving out condoms and education and try to treat pregnant mothers, but this is just a band-aid."

A national meeting in Pretoria last month confirmed this view but concluded that vaccines developed in the west are inappropriate for Africa because they target HIV cladeB, rather than the most common African clade, clade C. "As much as there have been reports of cross-reactive immune responses between the clades, they are not convincing," says Makgoba, who believes that South Africa has the capacity to develop its own vaccine-most likely through the Montagnier Institute if this gets the go-ahead-to be used throughout thecontinent. A task force has been appointed to head-up thevaccine initiative and through the USNIH HIVNET program, five sites are being established as AIDS vaccine test centers.

Finally, South Africa is al so redressing its deficit of public health researchers. After being disbanded in 1994 following the departure of thedirector, theNational AIDS Program-a group focused on public health-was reconstituted in June by the MRC within the Centre for Epidemiological Research in South Africa. Faced with an infection rate of 30 percent in pregnant women, new director DaveWilkinson's first job will beto implement a national program to reduce mother-to-child transmission using AZT and formula feeding. "We estimate that this will cost only one percent of thenational health budget, or US\$35 million, to cover the country."

Whilethecurefor HIV is unlikely to come from South Africa, many associated with the country believe that it is finally poised to make a real contribution to the effort.

Karen Birmingham, New York 